\title{
¿La ilustre Compañía? Memoria y hagiografía a través de las vidas jesuitas de los padres Juan Eusebio Nieremberg y Alonso de Andrade (1643-1667)*
}

\author{
José Luis Betrán \\ Universidad Autónoma de Barcelona
}

RESUMEN: El estudio de los «Varones Ilustres de la Compañía de Jesús» (16431667), obra de los jesuitas españoles Juan Eusebio Nieremberg y Alonso de Andrade, permite conocer no solo las claves del discurso hagiográfico barroco en la construcción de una identidad comunitaria en el seno de la orden, sino, y más importante, la lectura política que se desprende de algunas de las vidas que la configuran, con especial atención a las referidas a los generales jesuitas, en el contexto de la crisis política y religiosa vivida por la Compañía de Jesús en España en tiempos de Felipe IV.

\section{Palabras ClaVE: Jesuitas; Nieremberg; Andrade; Hagiografía; His- toria política; Representaciones.}

The Illustrious Company? Memory and hagiography through the lifes of the jesuits fathers Juan Eusebio Nieremberg and Alonso de Andrade (1643-1667)

ABSTRACT: The «Varones Ilustres de la Compañía de Jesús» (1643-1667) study, a work of the Spanish Jesuits Juan Eusebio Nieremberg and Alonso de Andrade, let us to know the keys of the baroque hagiographic discourse in the construction of a community identity inside the order and, what is more, let us discover a politic reading in the life of some members, with a special attention to the Jesuits generals, in a politic and religious crisis context lived by the Jesus Company in Spain in Felipe IV times.

* Este trabajo forma parte del proyecto de investigación «Memoria y Cultura religiosa en el mundo hispánico. 1500-1835» (HAR 2011-28732-CO3-01) del Ministerio de Economía y Competitividad del Gobierno de España. Para su elaboración se ha consultado del Archivo Histórico Nacional de Madrid (AHN), Archivo General de Simancas, en Valladolid (AGS), Biblioteca Nacional de Madrid (BN) y Biblioteca Universitaria de Barcelona (BUB). 


\title{
KEY WORDS: Jesuits; Nieremberg; Andrade; Hagiography; Political History; Representations.
}

\begin{abstract}
...y para tapar la boca a los que como perros rabiosos (que así los llama San Gerónimo, Rabidi adversus Christo in canes) de ver en tan poco tiempo crecer con tan lucidos aumentos nuestra religión de la Compañía, dizen y publican que no tiene Santos, ni milagros, ni doctores, ni Maestros de valía, mostrándoles a vista de ojos tantos dignos de sus escritos en el Catálogo de los Santos quantos contiene éste, y otros libros, pues los gloriosos Mártires solos, que derramaron su sangre por la Fe santa de Christo en espacio de cien años llegan a trescientos veinte y cinco, y los varones santos, cuyas vidas están en estos libros, pasan de seiscientos, sin otros muchos que se hallan ahora y descubrirán los tiempos.
\end{abstract}

Alonso de Andrade, Varones Ilustres en santidad, Letras y zelo de las almas de la Compañía de Jesús, Madrid, 1666, vol. V, Prólogo, fols. VII-VIII.

Los Varones ilustres de la Compañía de Jesús, del padre Juan Eusebio Nieremberg se imprimieron en Madrid, en cuatro tomos gruesos in folio, entre los años de 1643 y 1647, dentro del ciclo de escritos redactados por los jesuitas para conmemorar el primer siglo de vida de su institución. Los tres primeros volúmenes lo fueron en la imprenta madrileña de Maria de Quiñones, viuda sucesiva de dos impresores madrileños, Pedro de Madrigal y Juan de la Cuesta, instalada en la calle de San Eugenio: Ideas de Virtud en algunos claros varones de la Compañía de Jesús (1643), Firmamento religioso de lúzidos astros, en algunos claros varones de la Compañía de Jesús (1644) y Honor del Gran Patriarca San Ignacio de Loyola, fundador de la Compañía de Jesús, (1645). El último de esta primera serie, Vidas ejemplares y venerables memorias de algunos claros varones de la Compañía de Jesús (1647), fue editado en la imprenta de Alonso de Paredes, situada junto a los Estudios del Colegio Imperial ${ }^{1}$. Por la fecha de las censuras, su autor los concluyó antes de 1645 y, con toda probabilidad, el primero de los tomos previamente a 1638.

Tras el fallecimiento de Nieremberg en 1658, después de sufrir una larga enfermedad de parálisis durante trece años antes, fue su discípulo y compañe-

1 DELGADO CASADO, 1996, vol. II: 566-567; 511-512. SOMMERVOGEL, 18901932, vol. V: 1746. 
ro en el colegio de Madrid, Alonso de Andrade, quien continuaría su labor. Partiendo de los papeles que le dejara poco antes de su muerte, y atendiendo también al requerimiento de sus superiores para que prosiguiera la empresa recabando nuevas noticias biográficas sobre jesuitas singulares entre diversos provinciales en Europa y las Indias, Andrade compondría dos tomos más, que verían la luz finalmente entre 1666 y 1667, con el titulo de Varones Ilustres en Santidad, Letras y Zelo de las almas de la Compañía de Jesús, impresos en el taller de José Fernández Buendía². Significativamente, la primera vida relatada en el tomo $\mathrm{V}$ fue la de Nieremberg, que pasó así también a formar parte de aquella extensa galería de varones ilustres de la Compañía. Andrade añadiría, además, al final del último volumen un memorial que, por orden alfabético, recopilaría los mártires que la Compañía había tenido desde sus inicios hasta 1663, incluyendo información sobre su patria, lugar, fecha y la forma del martirio padecido ${ }^{3}$.

En su conjunto, estos seis voluminosos tomos publicados en apenas una veintena de años constituyeron una autentica enciclopedia de la «cotidiana santidad» jesuítica ${ }^{4}$, conteniendo las vidas de 525 personajes. Algo más de la mitad eran de origen hispano, un 13\% de portugueses y casi un 15\% de italianos. A pesar del universalismo de la Compañía, esta circunstancia remarca en parte el componente nacionalista de esta hagiografía, que parecía entroncar así con la historia providencialista que en España vino desplegándose durante los siglos XVI y XVII, en la que se insistía en el papel que sus súbditos habían desempeñado "en el porvenir de la Jerusalén terrestre» 5 .

El primero de los volúmenes se abría con un grabado (figura 1), de autor desconocido, que encerraba de manera emblemática el significado de la obra y que nos recuerda, de paso, la estrecha relación que la imagen reproducible y estandarizada circulando a la par con los libros tuvo en el nuevo régimen de comunicación visual contrarreformista que los jesuitas ayudaron a triunfar6. Sobre un claro encuadre trinitario, un reguero de jesuitas se ubicaban sobre dos caminos sin fin que se perdían en el horizonte, como milicias bien ordenadas, tras las figuras de los santos que habían alcanzado ya la beatificación o la canonización en el seno de la Compañía, y que se veían acompañados, en un primer plano, por otros personajes. El grabado presenta una articulada estructura jerarquizada de planos verticales y horizontales, testimoniales del principio de autoridad. En la parte superior Dios sostiene en su mano izquierda una esfera en cuya parte superior hay una cruz, símbolo de su supremo

\footnotetext{
2 ANDRADE, 1666, V: «Al lector».

3 ANDRADE, 1666, V: 722-754

4 BURRIEZA SANCHEZ, 2004: 152.

5 GUILLAUSSEAU, 99 (Universidad de Toulouse, 2007): 22-23.

6 DEKONINCK, 2005: 11-14.
} 


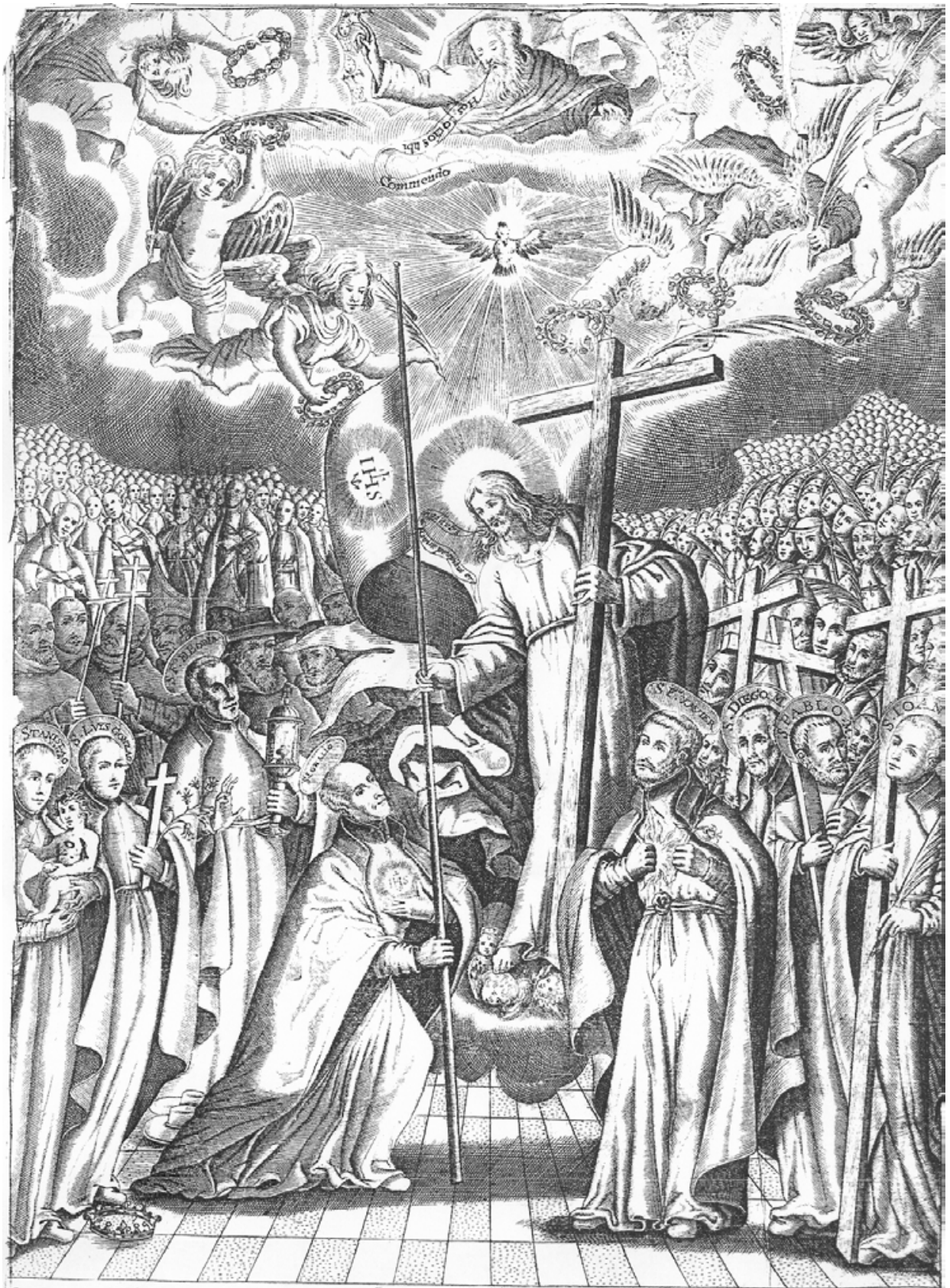

Sacra militia lesu nomme infignita Sub Crucis vexillo, Catholici nominis defenfiô et hęreticortm excidis clarifima. Ex Bullis Paull 3 . et Iulir-3-Confirmationis,Socictatis Iefith. ExBreui Gregorii 15 ad Carolum verdunenfem Epreophan : 
poder sobre los hombres. De su boca surge una leyenda escrita que expresa la misión providencial que encarga a los de la Compañía (Hos socios tibi comendo). Por debajo de éste aparece el Espíritu Santo, simbolizado por la paloma, y, en un tercer nivel, la figura central de Cristo, cuyo rostro aparece envuelto en un halo resplandeciente a cuya misma altura, en paralelo, aunque de menor tamaño, aparece envuelto en un nimbo de luz el anagrama de la Compañía de Jesús $(I H S)$. El Salvador agarra con su mano izquierda la cruz - signo de su pasión y emblema de la expiación y salvación de los hombres - mientras que con su derecha hace lo propio con el cetro, símbolo del poder y la autoridad suprema venida por Dios Padre y por Cristo sobre la tierra, y que, en un cuarto plano inferior, también es asido por el fundador Ignacio de Loyola, arrodillado ante el Hijo de Dios. De la boca de Jesús una segunda leyenda expresa la apertura del mundo que otorga a los ignacianos (Ego orbis ovrire pro filius ero).

Ignacio y Francisco Javier ocupan la parte central inferior de la escena, como fundadores de la Compañía y como únicos santos canonizados de la orden en 1622 por el papa Gregorio XV. Acompañan a San Francisco Javier a su derecha las figuras de tres apóstoles, simbolizando la acción misional y apostólica que los jesuitas han abrazado. Por un lado, San Diego, una de las denominaciones de Santiago Apóstol, patrón de España, significando la unidad de acción política y religiosa de la Compañía con la Monarquía Hispánica. Le sigue San Pablo, símbolo de la predicación del Evangelio entre los gentiles, cerrando por la derecha la imagen joven de San Juan Evangelista, «el amado», el apóstol al que Cristo en la cruz encargó el cuidado de su madre, la Virgen María, otro de los elementos fundamentales de la devoción jesuítica. Todos ellos asían la cruz, de menor tamaño que la de su Maestro, pero símbolo inequívoco de haber padecido también el martirio como aquél. Tras ellos, una multitud de jesuitas que llevan palmas y que reciben desde el cielo, lanzadas por ángeles, las coronas que simbolizan su triunfo sobre la muerte y el pecado, su inmortalidad. Detrás de Ignacio, en un plano más profundo, aparecen dibujadas las figuras de los beatos de la Compañía. En primer lugar, Francisco de Borja, el que fuera tercer general de la Compañía, que sostiene entre sus manos una custodia en que se guarda la Sagrada Forma. A su lado, la imagen adolescente de Luis Gonzaga, que tiene a su pies también una corona martirial, y Estanislao Kotska, con un niño Jesús acunado entre sus brazos, ambos símbolos del noviciado jesuita y de la intención pedagógica de la Compañía sobre la juventud europea. Una rama de lirio les acompaña como señal de su pureza, inocencia y castidad. Por detrás de este trío aparecen algunas cabezas adornadas con las mitras de la autoridad episcopal, acompañadas por la presencia de las cruces episcopales de dos barras, que simbolizan la disposición de la Compañía para emplearse en los ministerios religiosos que los representantes del Papa en las diócesis tengan a bien 
ordenarles. Tras éstos, una vanguardia de jesuitas con libros y plumas entre las manos — símbolos de su sabiduría—, se aprestan a la acción de estos cometidos.

Nieremberg seguía la estrategia retórica ya establecida por Ignacio, y proseguida por su primer biógrafo oficial, el padre Ribadeneira, de acercar cada vez más a los jesuitas al mundo de la milicia7 ${ }^{7}$ Lo cierto es que en la exposición de sus éxitos a los jesuitas les gustaba asemejarse a un ejército victorioso que caminaba en el cortejo de una Iglesia triunfante: un cuerpo eficaz que luchaba contra la herejía, como rezaba en la leyenda al pie del grabado, en la que también se recordaba, de paso, la confirmación otorgada de sus Constituciones por los Papas Paulo III y Julio III. A este respecto, en el prólogo del tomo IV, publicado en 1647, Nieremberg escribiría que

«...la gloria de la Compañía es que llamen a los herejes a sus religiosos galgos del papa, por servirse de ellos el Pontífice y los obispos de Septentrión para presas de mucha gloria de Dios, extirpando herejías y cazando almas para Christo» ${ }^{8}$.

Las dedicatorias de los cuatro primeros tomos lo fueron a miembros o deudos de la casa Sandoval, emparentada con quien fuera el tercer general de la orden, Francisco de Borja: la primera a Doña Inés de Guzmán, Marquesa de Alcañices, la segunda a Don Gaspar Hurtado de Mendoza, Moscoso, Osorio y Córdova, Marqués de Almazán; la tercera a Don Gregorio de Castellblanco, conde de Villanova y Sortella, señor de la casa de Goes; la última, al Cardenal Don Baltasar de Sandoval y Moscoso, arzobispo de Toledo. Por su parte, los dos volúmenes de Andrade, ya publicados bajo el reinado de Carlos II, los fueron a Don Andrés Bravo, obispo y señor de Sigüenza, del Consejo Real, y al propio valido y jesuita Juan Everardo Nithard, convertido en un «espejo de perfección...a los que mirarse los más fervorosos novicios de la Compañía» ${ }^{9}$.

\section{HÉROES VIRTUOSOS Y MÁRTIRES}

$\mathrm{Al}$ respecto de la naturaleza de su obra señalaba el propio Nieremberg su deseo de mostrar el carácter santo de muchos de sus compañeros de orden, guiados sin duda por la imagen de su fundador y patriarca Ignacio de Loyola, representado como un nuevo Abraham de los tiempos modernos:

7 FUMAROLI, 1999, vol I: 96

8 NIEREMBERG, 1647: Prólogo.

9 ANDRADE, 1667: Prólogo. 
Porque todos quantos juntó para fundar la Compañía fueron hombres señaladísimos, de los quales me ha parecido dar aquí alguna noticia de sus trabajos, empleos y misiones Apostólicas, juntamente con las virtudes de otros hijos de nuestro gran Patriarca, que con razón le compara el Concilio Tarraconense a Abraham, Padre de muchas gentes, porque lo fue de muchos santos ${ }^{10}$.

Las hagiografías o «vidas de santos» constituyen todavía hoy una fuente documental poco explorada por los historiadores, que las han considerado cargadas de altas dosis de relatos "prodigiosos» y por tanto ficticios, no históricos. Sin embargo, estas recopilaciones fueron ampliamente divulgadas durante el Renacimiento y el Barroco cuando por merced de la imprenta se multiplicaron los libros que las contenían ${ }^{11}$. Conocidas también como menologios, flores de santidad o «flos sanctorum», derivaban de la conocida leyenda áurea latina que el dominico Jacobo de Vorágine y sus colaboradores compusieron y reelaboraron en la segunda mitad del siglo XIII, y representan una santidad contextualizada en un tiempo y espacio determinados históricamente, que requiere cada vez más de análisis profundo por parte de la historia cultural ${ }^{12}$.

La edificación de la santidad representó en la Edad Moderna una gran actividad de la Iglesia católica. Los diversos ataques críticos de la Reforma provocaron una toma de conciencia que llevó al Concilio de Trento - en su sesión XXV, de 3 y 4 de diciembre de 1563-, a confirmar su visión doctrinal de los santos como modelos e intercesores, y con ello la eclosión y revalorización del género hagiográfico. No obstante, como es conocido, la Santa Sede sustituyó las canonizaciones espontáneas surgidas de la fama santitatis por el control de las autoridades episcopales y romanas. El siglo XVII fue consecuentemente un siglo en que la santidad estuvo bajo estrecho control, acentuándose la diferencia entre las prácticas populares de devoción y la hagiografía oficial, entre la denuncia de las primeras como «supersticiosas» y la solemnidad centralizada de las segundas por la Curia romana — con la Congregación de Ritos creada en 1588 - y la vigilancia desplegada por las diferentes Inquisiciones ${ }^{13}$. El proceso apostólico que condujera a la oficialización de nuevos santos debía pues verificarse mediante una encuesta de fama sanctitatis que identificase en ellos algunas de las principales virtudes de la santidad en la Época Moderna: las tres virtudes teologales (fe, esperanza y caridad), las cuatro cardinales (prudencia, justicia, fortaleza y templanza), amén de otras virtudes morales (las de los votos, mortificación y humildad) ${ }^{14}$.

\footnotetext{
10 NIEREMBERG, 1645: 365-366.

11 CARO BAROJA, 1985: 96.

12 RUBIAL, 1999: 14.

13 GOTOR, 2000: 280.

14 BURKE, 1987: 48-62.
} 
La instauración de los procesos de beatificación y canonización formaron parte de una empresa mucho más amplia de disciplinamiento, de reordenación fidelizada de las prácticas religiosas iniciada e impuesta en el seno de la Iglesia católica y que alcanzaría durante el pontificado de Urbano VIII su máxima expresión reglamentista con la prohibición explícita de abrir nuevas causas de canonización sin que hubiesen transcurrido al menos cincuenta años desde la muerte del candidato y de que, además, no existiera ninguna manifestación pública de culto previo. Estas medidas trataron de acabar con el culto de los siervos de Dios que todavía no hubieran sido beatificados y de frenar la escalada generalizada vivida en aquellos años dentro del mundo católico de querer en todas partes contar con un santo particular. Como consecuencia hubo una clara mengua de los procesos canónicos de ascenso a los altares finalmente exitosos habidos en el siglo XVII: de las 266 causas abiertas sólo la mitad alcanzarían algún fruto - 75 beatificaciones, 25 canonizaciones y 33 confirmaciones de culto- - siendo la mitad de los santos de origen ibérico ${ }^{15}$.

A pesar de ello, desde finales del primer tercio del siglo XVII, la Compañía de Jesús empezó a elaborar de manera masiva, manuscrita o impresa, colecciones de biografías y elogios fúnebres de jesuitas considerados insignes, fueran por sus virtudes religiosas, fueran por su ardor apostólico y misional, que serían propuestos como exempla vitae. Esta corriente de escritos se nos presenta como un género propio de la historiografía jesuítica. Desde 1611 la Congregación de los Provinciales reunida en Roma pidió formalmente al general Acquaviva que prescribiera su lectura en los refectorios de las comunidades en la vigilia en que se recordase el aniversario de la muerte de los mártires y confesos de la Compañía. El resultado fue la pronta circulación de algunos catálogos manuscritos por sus residencias que requerirían una cierta vigilancia de los propios generales. Los hubo de varios tipos: «oficiales», para toda la Compañía, con aprobación explícita del Prepósito General y bajo cuyo control se introducían las propuestas llegadas desde las congregaciones provinciales por los Procuradores enviados a Roma (el General y sus asistentes examinaban la proposición y dictaban su parecer, que si era favorable implicaba su inclusión en un Menologio Común); y las demás colecciones, de ámbito más privado, encargadas por los superiores y por los miembros de las congregaciones provinciales, pero a veces, también por los propios generales, pero sin ese carácter oficial ${ }^{16}$. Estos últimos podían quedar limitados a recopilar las vidas insignes de los jesuitas de una provincia en particular (tal es el caso del Catálogo de algunos varones insignes en santidad de la Provincia de Perú, impreso en Sevilla en 1633, o los nunca impresos de la provincia de Andalucía, posiblemente de Santibáñez, o para la de Aragón de Miguel Tor-

15 ARMOGATHE, 2005: 153-154.

16 MEDEIROS RODRIGUES, 2011: 3-4 
babi), o bien que incluyeran informaciones de varias provincias y asistencias, como fue el caso de la serie de Nieremberg y Andrade que el general Tirso González trató que prosiguieran los padres Bartolomé Alcázar y José Cassani. De este último se publicarían tres volúmenes entre 1734 y 1736 con el título de Glorias del Segundo Siglo de la Compañía de Jesús ${ }^{17}$.

En su función normal, los menologios se fueron formando a partir de las biografías y los elogios fúnebres, como narraciones ejemplares que pretendían modelar idealmente los comportamientos y las prácticas apostólicas de los jesuitas, especialmente de aquellos en formación. Aunque destinadas inicialmente a un autoconsumo en los colegios jesuitas, lo cierto es que muchas de ellas impresas, antes de ser incluidas en recopilatorios más extensos, circularon independientemente entre un público más amplio y externo en el que se buscaba generar también una cierta veneración hacia los miembros del Instituto. El propio Nieremberg publicó en 1631 una Panegírica narración de los 3 mártires de la Cia de Jesús que padecieron en la Provincia del Paraguay, así como una Vida de San Ignacio, en octavo, ciertamente polémica como tendremos oportunidad de comprobar, publicada el mismo año tanto en Madrid como en Zaragoza, y que sería reimpresa en 1636. En 1639 imprimió las vidas del padre Martín Gutiérrez, martirizado por los hugonotes franceses en 1574 y la de San Francisco Javier, que editó independientemente de la de Ignacio, en la que la había incluido tres años antes. Al año siguiente hizo lo propio con una vida del Padre Marcelo Mastrilli, misionero jesuita victima en Japón del ataque a Nagasaki tres años antes. El proceso para su beatificación había sido abierto en Manila en 1639 y Nieremberg tuvo un rápido acceso a su documentación, que empleó en su redacción ${ }^{18}$. También editó en 1644 una Vida de S. Francisco de Borja que conoció más tarde ediciones alemanas y francesas en 1671 y 1672, a caballo de la canonización del tercer general de la Compañía. Por su parte, Alonso de Andrade publicaría en Madrid en 1658 una Vida del Venerable Padre Francisco Aguado, confesor que fuera del Conde Duque de Olivares, y una Vida y milagros del beato S. Estanislao Kostka, en 1672, ambas incluidas en sus dos volúmenes de 1666-166719.

Aunque con la autonomía que implicaba siempre la narración individualizada de cada vida, su suma en recopilatorios, como los de Nieremberg y Andrade, nos muestra ese esfuerzo permanente entre los miembros el Instituto por la formación de un cuerpo comunitario de la Compañía, cuya joven identidad —apenas un siglo de existencia—, había ya sido puesta a prueba reiteradamente desde sus mismos inicios no sólo por el mundo protestante sino,

17 MEDEIROS RODRIGUES, 2011: 14-15.

18 NIEREMBERG, 1645: 225.

19 PALAU y DULCET, 1958, XI: 43-48. 
por otras órdenes religiosas de mayor tradición en el propio seno del catolicismo ${ }^{20}$.

Aunque no fue exclusivo de los jesuitas, la imitatio Christi, un elemento clave para entender la devoción postridentina, se convirtió en el modelo de comportamiento propuesto repetidamente en la narración de la vida de los santos o ilustres del Instituto21. Como ha señalado acertadamente Rico Callado, este cristocentrimo se vertebró sobre diferentes ejes. El primero de ellos giró en torno a la penitencia, convirtiendo su exhibicionismo literario en un reclamo proselitista y de conversión. Así, el espectáculo de las mortificaciones, de la pobreza de vestimentas, la renuncia a la comida, la bebida, el sueño, a la propia familia, las incomodidades de las peregrinaciones misionales, las persecuciones y contratiempos padecidos en el asentamiento territorial de los colegios, entre otros, resultaron episodios recurrentes en las hagiografías jesuitas, muy relacionados con el uso del acto de contrición ${ }^{22}$, y al que ya hemos aludido en otros trabajos como elementos básicos de esa construcción autocomplaciente de la imagen de la Compañía ${ }^{23}$. Por otro lado, la pureza del alma o los buenos sentimientos de estos hombres también fueron un aspecto obviamente destacado. La oración mental, bajo una clara dimensión afectiva que moviera hacia la acción a estos personajes, era otro de los ejes principales que debía reforzar las vocaciones de los sujetos a través de la lectura de sus vidas ejemplares. Los Ejercicios ignacianos precisamente apelaban a la reflexión sobre la Pasión de Cristo como un elemento de santificación personal y de servicio al prójimo ${ }^{24}$. Contemplada o imitada, la Pasión del hijo de Dios puso el tema de los martirios como un tercer nervio ejemplificante de las obras de Nieremberg y Andrade.

El análisis de los datos que aporta este último en el volumen VI de la obra (Cuadro 1), permite extraer algunas consideraciones de cierto interés. En primer lugar, ponen de relieve el rol fundamental que estos mártires tenían para la Compañía por cuanto su sacrificio vinculaba los dos mundos o contextos geográficos-culturales donde se producían tales episodios: la Europa dividida por las luchas religiosas entre católicos y protestantes y las misiones ultramarinas. En Europa cobraron especial relevancia las muertes resultantes de los esfuerzos por recuperar o mantener viva la fe católica en territorios que habían pasado a la Reforma. Destacaban así los martirios sucedidos en Alemania durante el periodo de la Guerra de los Treinta Años, los de los jesuitas polacos en sus conflictivas relaciones con el luteranismo sueco o la ortodoxia

20 MORENO MARTINEZ, 2010: 80.

21 RICO CALLADO, LXX, Extra I (Madrid, enero-junio 2013): 128.

22 RICO CALLADO, LXX, Extra I (Madrid, enero-junio 2013): 132-134.

23 BETRAN MOYA, 65 (Valencia, 2009): 175-179. BETRAN MOYA, 2012: 136-143

24 GARCIA ESTEBANEZ, 2007: 696. 
rusa y, de manera destacada, los martirios padecidos en la Inglaterra anglicana, que reflejaban el comportamiento heroico de aquellos mártires que soportaban acciones judiciarias, torturas y muerte en nombre de la fe. Ahorcamientos y descuartizamientos solían ser las formas más habituales de su ejecución, como lo refleja la descripción de los martirios de Edmundo Campiano en 1581 o de Edmundo Oldcorro, en 1606, entre otros. En el caso de este último Dios establecía prueba de su inocencia al hacer que de sus entrañas saliera durante 16 días un fuego que no pudieron apagar los herejes, cesando al día siguiente, de cuyas cenizas «brotó una corona de grama olorosa, en señal de su inocencia» ${ }^{25}$. En tierras católicas apenas hay sucesos destacables más allá del martirio del portugués Manuel Fernández en 1555 en Ebora, cuando los amantes de una mujer a la que había reformado «le salieron al camino y le molieron los huessos y la sangre, de que murió», siendo enterrado por el propio Infante Don Enrique «como a mártir de la castidad» ${ }^{26}$; o el del jesuita andaluz Antonio López a manos de unos moriscos cuando volvía de Jesús del Valle a Granada en $1579^{27}$.

CuAdro 1. MÁRTIRES DE LA COMPAÑía DE JESÚS DESDE SU FUNDACIÓN HASTA 1663 SEGÚN LA RELACIÓN DE ALONSO DE ANDRADE

\begin{tabular}{|c|c|c|c|c|c|c|}
\hline \multirow{2}{*}{$\begin{array}{c}\text { Nacionalidad del } \\
\text { mártir }\end{array}$} & \multicolumn{4}{|c|}{ Continentes } & \multirow[t]{2}{*}{ Total } & \multirow[t]{2}{*}{$\%$} \\
\hline & Europa & África & Asia & América & & \\
\hline Alemanes & 9 & & & & 9 & 2,84 \\
\hline Flamencos & 8 & & 1 & 1 & 10 & 3,15 \\
\hline Holandeses & 2 & & & & 2 & 0,63 \\
\hline Franceses & 7 & & & 9 & 16 & 5,05 \\
\hline Polaco-lituanos & 10 & & 1 & & 11 & 3,47 \\
\hline Bohemios & 4 & & & & 4 & 1,26 \\
\hline Húngaros & 1 & & & & 1 & 0,32 \\
\hline Transilvanos & 2 & & & & 2 & 0,63 \\
\hline Portugueses & 1 & 13 & 30 & 53 & 97 & 30,60 \\
\hline Hispanos & 2 & & 15 & 40 & 57 & 17,98 \\
\hline Italianos & 1 & 2 & 20 & 5 & 28 & 8,83 \\
\hline Ingleses & 21 & & & & 21 & 6,62 \\
\hline Irlandeses & 7 & & & & 7 & 2,21 \\
\hline Escoceses & 1 & & & & 1 & 0,32 \\
\hline
\end{tabular}

25 ANDRADE, Alonso de, 1667: 721-722.

26 ANDRADE, Alonso de, 1667: 743

27 ANDRADE, Alonso de, 1667: 754. 


\begin{tabular}{|c|c|c|c|c|c|c|}
\hline \multirow{2}{*}{$\begin{array}{c}\text { Nacionalidad del } \\
\text { mártir }\end{array}$} & \multicolumn{4}{|c|}{ Continentes } & \multirow[t]{2}{*}{ Total } & \multirow[t]{2}{*}{$\%$} \\
\hline & Europa & África & Asia & América & & \\
\hline Chinos & & & 1 & & 1 & 0,32 \\
\hline Japoneses & & & 46 & & 46 & 14,51 \\
\hline Otros & & 1 & 4 & & 5 & 1,58 \\
\hline Total & $\begin{array}{c}76 \\
\left(23^{\prime} 97 \%\right)\end{array}$ & $\begin{array}{c}16 \\
(5,05 \%)\end{array}$ & $\begin{array}{c}117 \\
\left(36^{\prime} 91 \%\right)\end{array}$ & $\begin{array}{c}108 \\
(34,07 \%)\end{array}$ & 317 & \\
\hline
\end{tabular}

Fuente: Alonso Andrade, Varones Ilustres en Santidad, Letras y zelo de las almas de la Compañía de Jesús, Madrid, José Fernández de Buendía, 1667, Vol. VI, pp. 722-754.

Pero fueron los continentes americano y asiático los que tuvieron un mayor número de mártires jesuitas, en correspondencia con el despliegue misional de la Compañía. Los jesuitas portugueses aportaron un tributo importante en sangre. Aunque no en su totalidad -32 eran portugueses y ocho españoles-, una buena parte pertenecen a la expedición del que fuera elegido primer Provincial del Brasil, Ignacio de Azevedo, que en julio de 1570, mientras se dirigían hacia el Nuevo Mundo, fueron martirizados a manos de corsarios comandados por el capitán galo Jacques Soria en el mar frente a las Islas Canarias, siendo el martirio colectivo del mayor número de jesuitas de la Época Moderna. La difusión del relato de su martirio con el fin de obtener su canonización, además de estimular una multiplicación de las peticiones de jesuitas europeos sin precedentes que quisieron ser enviados con ardor a las misiones americanas o asiáticas para ser martirizados a imitación de Azevedo y sus compañeros, representó un claro esfuerzo de la Provincia de Brasil por contrarrestar el predominio de Oriente en el panorama misionero portugués ${ }^{28}$. Por lo que se refiere a los misioneros españoles, la expansión septentrional en el virreinato de Nueva España y la región de Florida (Bernardino de Cisneros, Diego de Orozco, González de Tapia, Fernando de Tovar, Francisco Aranda, Gabriel Gómez...) junto a los escenarios guaraníes en el sureste del territorio peruano (Gaspar Osorio, Jerónimo de Moranta, Juan del Castillo, Miguel de Urrea...) contemplan el mayor número de martirios. Las flechas y los golpes de las mazanas suelen ser las formas habituales del suplicio, que también padecen los nuevos misioneros franceses asentados en las tierras de Nueva Francia como el caso de Juan de Brebeuf en 1649, después de haber convertido más de 7000 hurones, a manos de los indios iroqueses, cuya descripción constituye un verdadero jardín de los suplicios:

28 OSSWALD y HERNANDEZ PALOMO, 2009: 141. 
... arrancáronle la piel de la cabeça y las uñas; atáronle a un palo y le açotaron, haziendo una llaga todo el cuerpo; sembráronle de ascuas y echáronle encima agua ardiendo en oprobio del Baustimo. Cortáronle las manos y la lengua, quebráronle la boca con una piedra, quemáronle los costados y los riñones con seques encendidas en fuego; al cuello le pusieron cadenas ardiendo, que caían con laminas encendidas sobre el pecho; ciñéronle un cíngulo de pez y resina ardiendo; después le cortaron los pies, haziéndole pedazos poco a poco. Para mayor tormento le fueron cortando las carnes, dexando desnudos los huesos. Últimamente le abrieron el pecho, y le sacaron el coraçón, y se lo comieron en su presencia, y con este penoso martirio fue coronado al Cielo ${ }^{29}$.

El espectáculo de la sangre vertida injustamente y el de la eliminación del Bien por el Mal trataba de provocar en los fieles una reacción de emoción y de veneración que podía desembocar en su culto ${ }^{30}$. El continente asiático, que había visto el primer mártir de la Compañía en el sur de la India en 1549, Pietro Antonio Criminali, vería las mayores sofisticaciones en este ámbito. El escenario japonés fue el que mayores miradas atrajo. No en vano fue aquí donde fueron mayores las matanzas de religiosos de diferentes órdenes (en 1587 en Nagasaki, en 1612-13 en Osaka, Mino, Hachijòjima, Arima, Iwami, Itisuki y Edo; de nuevo en Nagasaki en 1622, 1633, 1634 y 1637), y donde la actuación de los jesuitas despertó mayores recelos críticos por parte de las restantes órdenes religiosas presentes en el país ${ }^{31}$. Así lo muestra, por ejemplo, la contundencia de los memoriales presentados ante la Corona por el provincial dominico en Japón, fray Diego Collado, y los padres fray Pedro de Santa Catherina y fray Domingo de Castellet, en marzo y agosto de 1622. En ellos se acusaba a los jesuitas de pretender monopolizar la evangelización del Japón excluyendo a las demás órdenes con supuestas bulas otorgadas por Gregorio XIII; de haber incitado las matanzas contra ellos en el pasado para echarlos del país, o de querer sacar todo el beneficio del comercio de oro y seda desde la India y China hacia el Japón, cosa contraria al espíritu de humildad y pobreza con que los ignacianos pretendían presentarse ante los japoneses ${ }^{32}$. Cárceles, destierros, arrojamientos a estanques de aguas heladas, crucifixiones, hogueras, degüellos y, sobre todo, el más temido de los tormentos por los cristianos, el de la cueva o fosa, especie de pozo séptico sobre el que era colgado bocabajo el mártir —con un agujero en medio de las dos puertas que cerraban la fosa para que solo cupieran las piernas - inhalando las pútridas emanaciones, constituían toda una galería de los horrores, no solo con los que impresionar la imaginación de los lectores europeos, sino con los que refrendar la política de la Compañía en

29 OSSWALD y HERNANDEZ PALOMO, 2009: 737-738.

30 VAUCHEZ, 1988: 180.

31 ALABRUS IGLESIAS, 2013: 237-239.

32 VICENS, Fr. Gaspar, Mss. 1009: Fols. 107v-120r. 
Japón ante los ojos de los católicos europeos con los 78 mártires ignacianos habidos, aunque 46 de ellos fuesen japoneses.

La repetición de este modelo cristocéntrico en las hagiografías de Nieremberg y Andrade tenía pues, como objetivo, repetir el sentido y la trascendencia del sufrimiento en la vida, dotándolo de un contenido positivo y espiritual $^{33}$. El infierno martirial se convertía entonces en una sombra y un atisbo del paraíso venidero. La lectura cotidiana y calendaria que se pudiera hacer de aquellas vidas inscribía el tiempo humano dentro del tiempo sagrado del mito forjado con Cristo. El martirio de los santos, en cuanto actualización repetitiva y permanente de la imitatio christi, mantenía a la gente dentro de un mundo sagrado y grave ${ }^{34}$. Nieremberg y Andrade no hicieron más que trasladar a sus obras lo que el padre Ribadeneira había hecho al recuperar con su Flos Sactorum (1599-1601), el encanto y el entretenimiento que había caracterizado el primer contacto que Ignacio de Loyola tuvo antes de su conversión, con las vidas de los santos ${ }^{35}$. De Ribadeneira escribiría Nieremberg que:

...tanto fue siempre el gusto y afición con que meditava las vidas y ejemplos de los Santos, que parece que lo disponía nuestro Señor para escribir sus historias con tanto acierto y piedad, como las escrivió, y para tanto provecho y reformación de las costumbres ${ }^{36}$.

La devoción y el placer que podía despertar su lectura no podían ser más que un primer peldaño hacia la ejemplaridad práctica que debían despertar aquellas Vidas, y el propio Nieremberg, convertido en el hagiógrafo más importante de la Compañía en España durante el reinado de Felipe IV, sería el encargado de realizar las adiciones de aquella obra en las sucesivas reimpresiones que se hicieron de la misma a partir de $1643^{37}$, constituyendo una auténtica tercera parte.

\section{LUCES Y SOMBRAS}

Juan Eusebio Nieremberg es todavía hoy una figura histórica claroscura ${ }^{38}$. Nacido en 1595 en Madrid, sus padres, Gottfried Nieremberg y Regina Ottin,

33 ÉLIADE, 1969: 112.

34 DUPRONT, 1996: 530.

35 DARNIS, 2005: 442-443.

36 NIEREMBERG, 1647: 447.

37 RIBADENEIRA, 1643.

38 Su más célebre conocedor, Hugues Didier, ya apuntó hace años las dificultades que suponía la documentación de su vida, especialmente por lo que hacía referencia a sus últimos años. DIDIER, 1976: 9 y 40-41. 
llegaron a España al servicio de la emperatriz María de Austria, viuda de Maximiliano I de Austria, y hermana de Felipe II. Tras una intensa experiencia espiritual a los dieciséis o diecisiete años, Juan decidió renunciar a la carrera militar propuesta por sus padres — con gran disgusto y oposición de éstos a su decisión de entrar en la Compañía-, y pasó a formar parte de la Compañía de Jesús en 1614 de la mano de su maestro, el padre Francisco Aguado, confesor años más tarde del conde-duque de Olivares y uno de los hombres fuertes de la casa de los jesuitas en Madrid. Según Hugues Didier, Aguado fue el responsable de inculcarle como novicio, junto a una rigurosa aversión del mundo, un ardiente amor por la Cruz y la ascesis cristiana, así como una ternura casi idólatra por el fundador de la orden ${ }^{39}$.

Al contrario que otros jesuitas no se vio atraído por las misiones, y su personalidad tranquila se volcó en el saber entre libros. Estudió Artes y Teología en Alcalá. Ordenado sacerdote en 1623 fue desde 1628 y hasta su muerte uno de los docentes más insignes del Colegio Imperial, a cuyo cargo estuvieron las cátedras de Sagrada Escritura y de Ciencias Naturales. Profeso de cuatro votos, fue también Rector de la casa de Probación de Madrid y Maestro de Novicios. En la corte alcanzó un cierto relieve que le granjeó respeto. Confesor de Margarita de Saboya, duquesa de Mantua, nieta de Felipe II y prima de Felipe IV ${ }^{40}$, también fue consejero del rey y de su valido, y un intelectual comprometido con los debates que afectaban a la religión católica en materia de doctrina entre el Papado y la propia Monarquía Hispánica ${ }^{41}$, participando en la Junta Real sobre la Inmaculada Concepción, tema al que dedicó algunas obras. Muerto en 1658, su sepelio fue sufragado por Don Cristóbal Crespi de Valdaura, Vicecanciller de Aragón y, según su biógrafo Alonso de Andrade y el también jesuita Manuel Najera, que predicó el sermón por sus exequias, se convirtió en una manifestación plenaria y masiva de la proclamación de su santidad ${ }^{42}$. Su cadáver, trasladado del colegio Imperial a la iglesia de las Descalzas Reales de Madrid, tras el oficio que le hiciera Don Francisco de Borja, nieto del que fuera tercer general de la Compañía y capellán mayor de las Descalzas, quedó colocado en una bóveda debajo del prebisterio, bajo la cual, el propio Crespi sería enterrado años más tarde por la veneración que le sentía ${ }^{43}$.

Nieremberg escribió un número prodigioso de obras, la mayor parte de ellas teológicas, místicas, filosóficas, pero también políticas. Andrade cita de él al final de su menologio un total de 35 obras impresas en castellano y 26 en latín. También nos dejó una imagen de él como hombre recogido y solitario,

39 DIDIER, 1976: 50-51.

40 ANDRADE, 1666: 19

41 ANDRADE, 1666: 26. BROGGIO, 2009: 156-166.

42 ANDRADE, 1666: 49-50. NAJERA, 1658: 16v.

43 BALLESTEROS ROBLES: 
dedicado por entero al estudio, que retirado «del bullicio de la Corte, tomó un aposento en lo más retirado de la casa, quatrocientos, i más passos de la portería» donde vivía "como en soledad del yermo, entregándose todo a la contemplación, y licion (sic), y al estudio de los libros», no saliendo de casa si no era «compelido de gravísima causa» ${ }^{44}$.

Pero lejos de esa imagen apacible de retiro y estudio, su personalidad no quedó al margen de polémicas y de un activismo político. Inclinado hacia la alianza entre Viena y Madrid, que mediante la unión de ambas ramas de la Casa de Austria pudiera revivir el antiguo ideal carolingio como solución evidente a los problemas de la Monarquía Hispánica ${ }^{45}$, en 1643 escribió un pequeño tratado para la formación del príncipe heredero Baltasar Carlos, que dedicó a su madre, la reina Isabel de Borbón. En él hacía un repaso de los miembros de la casa de Austria y de los reyes castellanos fundadores del imperio hispánico y cuyas virtudes, a su juicio, debía heredar el futuro rey de España ${ }^{46}$. Un año antes compuso, asimismo, un pequeño tratado político titulado Causa y remedio de los males públicos, que dedicó al Conde Duque de Olivares ${ }^{47}$, que no sería el primero de los dirigidos al valido pues el confesor de éste, el padre Francisco Aguado, ya había hecho lo propio en 1640 a propósito de la revuelta catalana ${ }^{48}$. Impreso tras la muerte del Cardenal Infante y las sublevaciones catalana y portuguesa, en él, no sin pequeñas dosis de crítica arbitrista también presente en otros escritos jesuíticos del momento focalizados en la sobrecarga fiscal y la adulteración monetaria que sufrían los súbditos de la Corona, puso especial énfasis en la necesaria regeneración moral y religiosa que súbditos y gobernantes precisaban para enderezar el desastroso curso de la guerra y las revueltas, poniendo a la Iglesia como intercesora necesaria ante las desgracias que la Providencia había enviado a la Monarquía Hispánica.

Si complejo fue el contexto político que le tocó vivir a Nieremberg, no lo fue menos para el resto de los miembros del Instituto en España, plenamente conscientes de su realidad. Aunque la escalada política de la Compañía se había hecho imparable primero con Lerma y después, y sobre todo, con Olivares y sus confesores, este «brillo» cortesano y político, cargado de influencia y poder pero también del constante recurso al amparo del poder político como cobertura y salvaguarda ante las quejas de los restantes institutos religiosos, fue directamente proporcional a la crisis interna que vivía la Compa-

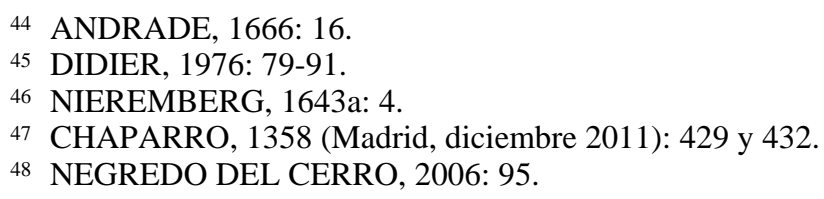


ñía por aquellos tiempos, como nos ha recordado Julián Lozano ${ }^{49}$. La pujanza en la corte también tuvo su punto de fractura en la existencia de proOlivaristas y antiOlivaristas desde finales de los años treinta. La Compañía por momentos pareció ingobernable y muy lejos de esa imagen triunfal siempre pretendida. A nivel interno, las visitas de las provincias detectaban fallos diversos pero quizás el más destacado y generalizado, sobre todo en Andalucía y Toledo, era la existencia de partidos clientelares en los propios colegios. Aunque al finalizar el generalato de Acquaviva la Compañía en España se había extendido geográficamente de manera impresionante con más de ochenta y cinco domicilios, el número de sus efectivos en la península en realidad decreció de 2.173 en 1616 a poco más de 1800 en 1652, y con numerosos casos de fuga y expulsión ${ }^{50}$. Las muestras de erosión de su prestigio social también fueron constantes en aquellos años: la Compañía tuvo problemas para asentarse en algunas ciudades, como el caso de San Sebastián ${ }^{51}$. Asimismo, los jesuitas sufrieron una difusión masiva de panfletos, libelos y pasquines contra ellos, con un impacto muy significativo de la famosa Monita secreta, traducida por un personaje atrabiliario como el excarmelita Juan de Espino. El texto de Juan de Mariana sobre las enfermedades de la Compañía corría dentro pero también fuera de los colegios, con lo que ahora muchos podían diagnosticar sus males y atizarlos contra los ignacianos en su desprestigio $^{52}$. Los choques con el resto de religiones fueron también feroces, como lo demuestra la revuelta de las andaluzas contra los jesuitas para marginarlos en $1628^{53}$. Algo similar ocurrió con las universidades, con el voto tomista de Salamanca, en 1627, o la batalla campal desatada por la creación de los Estudios Reales en Madrid ${ }^{54}$. Ni siquiera el triunfo del inmaculadismo frente a los dominicos se pudo saborear adecuadamente en aquellos años: el protagonismo de inmaculadistas desaforados como el padre Juan Bautista Poza, con sus obras prohibidas en el Índice romano, sus continuos memoriales inundando la corte... provocaban la media sonrisa satisfecha entre los dominicos, mostrándonos además la turbulenta tormenta en que se encontraba sumergida la Compañía entre el poder de Roma y el regalismo de Felipe IV. Las diatribas del padre Poza llamando ignorantes a los mendicantes o los comentarios de otros hermanos de hábito menospreciando su labor afirmando que ellos solos valían para «cultivar la viña del señor» y llamándoles desde los púlpitos «inobedientes al Papa» e «introductores de cismas en la Iglesia», no generaban

49 LOZANO, 2005: 187-270.

50 ASTRAIN, 1916, vol. V: 49.

51 ASTRAIN, 1916, vol. V, 21-22. Estado, AGS, Legajo 2646, doc. 31.

52 CATTO, 2012: 940.

53 NEGREDO del CERRO, 2006: 82-88. BIRELEY, 1981: 20-21. BIRELEY, 2012; 56-57

54 SIMON DIAZ, 1992: 72-91. 
precisamente amigos entre el clero regular y potenciaron muchos de los odios e inquinas hacia los jesuitas en aquellos años ${ }^{55}$.

Asimismo, el cuarto voto jesuita volvió a convertirse en un tema incómodo para los jesuitas españoles. Las sospechas de la inclinación profrancesa en la Guerra de los Treinta Años por parte del general Vitelleschi y del papa Urbano VIII en los conocidos episodios del padre Lamormaini y las censuras contra la obra del jesuita Puente Hurtado ${ }^{56}$, volvieron a poner sobre la mesa la posibilidad de una escisión de la Compañía. Felipe IV llegó a amenazar al propio Pontífice, a través del Cardenal Gaspar Borja y Velasco en marzo de 1632, con la posibilidad de forzar la convocatoria de un Concilio que pudiera provocar su destitución ${ }^{57}$, y al General de los jesuitas también le hizo saber, a través de una carta remitida por el padre La Palma, su deseo de que ningún ministro se confesase con los jesuitas, pretendiendo además que se nombrase en España un comisario general con poderes similares a los comisarios franciscanos, que el generalato se alternase entre España y otras naciones y, por último, que el Prepósito General en persona visitase las casas de la Compañía en España. Como señala Astrain, el viejo sueño de españolizar la Compañía por parte de la Monarquía siguió bien vivo durante el reinado de Felipe IV58. Sólo las disculpas de Vitelleschi ante el Conde-duque y la movilización de los jesuitas próximos a la Corte, incluyendo al propio confesor del valido, lograron atemperar el conflicto ${ }^{59}$.

En aquel delicado contexto político-religioso, hasta el mismo Nieremberg tuvo conflictos con las Inquisiciones española y romana por causa de algunas de sus obras. En ocasiones fue por circunstancias ajenas y posteriores a su propia muerte. En 1658 la Inquisición zaragozana detectó en las librerías de la ciudad varios ejemplares de algunas de sus obras distribuidos por un mercader de libros valenciano llamado Crespín Roman, que habían sido impresas en Barcelona en 1644 y 1649 por el librero catalán Pedro Lacavalleria, muerto en 1645, y por un hijo de éste, Antonio, que fue llamado a declarar ante el Santo Oficio. En plena revuelta catalana, éstos habían incluido en algunos títulos del jesuita que pretendían vender en Francia (en concreto la Curiosa filosofía y Tesoro de maravillas de la naturaleza y la Oculta Philosophia), sendas dedicatorias al Cardenal Mazarino y al duque Enrique de Lorena, en que se realizaban descalificaciones hacia la corona española, que era considerada como una autentica amenaza para el catolicismo, pues era la razón de una «segunda esclavitud» que no perdonaba ni «a las llaves de San Pedro», en

\footnotetext{
55 MORENO MARTINEZ y PEÑA DIAZ, 2011: 159-161.

56 NEGREDO del CERRO, 2012: 166-170.

57 VISCEGLIA, 2003: 167-170.

58 AGS, Estado, Leg. 3011.

59 ASTRAIN, 1916, vol. V: 201-204. Estado, AGS, Leg. 2999.
} 
clara referencia al Papado. Según los agustinos Martín Francés y Felipe Cirera, que formaban parte de la comisión censora del Santo Oficio, se trataba de proposiciones injuriosas «porque en la primera hacen a la Monarchía de España infiel; y en la segunda opuesta y enemiga de la Iglesia todo lo qual es sembrar sedición, intentarla y desearla entre una Monarchía tan cathólica y la Iglesia» ${ }^{60}$.

También, la publicación aquel mismo año del sermón por las honras fúnebres de Nieremberg a cargo del jesuita Manuel de Nájera, predicador real, fue objeto de censura por la Inquisición española ${ }^{61}$. En este caso, los argumentos de la censura fueron diversos. En primer lugar, se aludía al hecho de carecer de licencia y aprobación de los superiores de la orden para su publicación, como ordenaba el Santo Concilio de Trento. Por otro lado, se censuraba la indecencia de expresiones tales como «aviéndose concebido a vista de Cristo crucificado», en alusión a la concepción que su madre Regina Ottin, ya mayor de 50 años, habría conseguido de las plegarias hechas ante el Cristo de San Martín de Madrid para quedar en cinta, considerando que aunque la intención del predicador era otra podía dar lugar a indecorosos pensamientos. Pero los censores del Santo Oficio se mostraban especialmente preocupados por la insistencia del predicador en mostrar las aparentes señales de santidad del difunto: milagros, revelaciones, olor de santidad del cuerpo muerto o el exceso deleitoso en el uso de penitencias por parte de aquél, que era definido con expresiones excesivamente vulgares como decir que de las mismas tenía más gusto «que la damería en el varro». A esto había que sumar la desmesura con que Najera hablaba de sus virtudes al considerarlo «segundo Joseph en la Profecía», «Sagrado Sinay ardiendo en celosos incendios», «evangélica trompa en todo el mundo», «segundo Moysés y Salomón segundo en la sabiduría», «discípulo de San Pablo» o señalar que el padre Eusebio estaba en el cielo «con grandes grados de gloria», y que su presunta santidad era extensible a sus discípulos «que también son corona». Incluso, se subrayaba la temeridad de insinuar que habría recibido la gracia divina ya en el vientre materno, antes del bautismo, o el hecho, extraordinario, de concitar junto a él a numerosos ángeles, elemento de necesaria inspección, pues no a todos estaba reservada tal deferencia:

Esta Proposición si se entendiesse que eran Ángeles de su Guarda sería materia que obligaría a particular inspección. Porque aunque sea probable según que advierte el padre Suarez, lib. 6 de los Ángeles cap $17 \mathrm{n}^{\circ} 24$ que la Madre de Dios tuvo dos Ángeles de su guarda, y que lo mesmo se puede entender suceder a los Apóstoles y a todos los pontífices de la Iglesia y personas deputadas para grandes

60 AHN, Inquisición, 4480, Exp. 9.

61 AHN, Inquisición, 4480. Exp. 11. 
ministerios, ninguno ha dicho que mas de dos ángeles de la guarda haya dado Dios a alguna pura criatura.

En definitiva tenia «el sermón sembrada y repetida alabanzas notabilíssimas del Padre Eusebio que pudo ser que él lo mereciese para con Dios, pero que no se pueden decir de una persona que la iglesia no ha calificado», contraviniendo, a pesar de la protesta inicial de su autor de no pretenderlo, las disposiciones en esta materia decretadas por Urbano VIII.

En todo caso llovía sobre mojado, pues el propio Nieremberg también había recibido años antes censuras similares por la edición que hiciera de una Vida de Ignacio de Loyola en 1631 y que, finalmente, después de un largo proceso de reelaboración del texto en sucesivas ediciones, fue incluida en el tomo III de las Vidas Ilustres en 1645.

El rastro de aquella denuncia nos la da una carta que envió el General Vitelleschi al provincial de Toledo el 20 de marzo de 1638, en la que le escribía que no le habían llegado las censuras previas de una obra que venía preparando, los Varones ilustres de la Compañía de Jesús, que posiblemente por aquellas fechas ya tenía compuesta Nieremberg. La desconfianza hacia el jesuita era evidente por parte del General, que insistía en que no se le otorgara licencia para la impresión si primero no se le remitía el libro «para que yo lo lea o le haga ver, y se examine si lo que contiene es conforme a lo que en hecho de verdad pasó», pues consideraba que dada la naturaleza de la obra, en la que Nieremberg señalaba que solo había hecho traducción de cosas anteriores ya repartidas en diversos lugares de la Historia de la Compañía y otros autores, sólo en Roma se conservaban los papeles auténticos que podían verificar lo que hubiera redactado o traducido, pues «quedé escarmentado de la Vida de Nuestro Padre San Ignacio que el P. Eusebio estampó, porque aunque es autor pío y docto, no todo lo que en ella se decía estaba ajustado a lo puntual de la historia». En una carta previa a ésta, también escrita en 1634 por Vitelleschi al padre Juan Montalvo, Provincial de Toledo, el General le advertía que:

En la vida de San Ignacio por el P. Eusebio se han reparado algunas cosas, como llamar santos y beatos a hombres no beatificados...En un milagro del estudiante de Florencia hay cosas no ajustadas a la verdad...La Sagrada Congregación del Índice me ha cometido la enmienda de esto. Ordeno a V. R. avise al dicho Padre, para que lo quite lo que va notando y lo demás que viere, que o por no estar bien averiguado o por decirse con alguna exageración, puede ser ocasión de tropiezo ${ }^{62}$.

Fuera por la denuncia expresada por la autoridad romana o por el propio anhelo de evitar cualquier escándalo que afectara a la reputación de los jesui-

62 ASTRAIN, 1916, V: 104-105. 
tas, la Vida de Ignacio de Nieremberg fue sometida a la censura interna de la propia Compañía ${ }^{63}$, lo que explica algunos de los cambios habidos en las ediciones posteriores a la primera de Madrid de $1631^{64}$. Así, a partir de la edición de 1636 los términos de beato o santo desaparecieron para los que realmente no hubieran sido confirmados por Roma y en los volúmenes de los Varones Ilustres, Nieremberg introdujo siempre una protesta inicial en que alertaba que el uso que pudiera hacer de «las palabras Santidad y Santo, y otras semejantes», las realizaba «en el sentido común, que en el modo de hablar Español se suelen atribuir aun a los que viven por una vida de gran edificación y ejemplo, al parecer humano, sin que por ellas y por todo lo que escrivo sea visto prevenir el juicio de la Iglesia, que califica las verdaderas santidades, al que me sujeto en todo» 65 .

También Nieremberg suprimió a partir de 1636 el controvertido episodio del milagro que Ignacio había obrado al resucitar con sus plegarias a un novicio florentino de la Compañía que se había suicidado por los castigos que le había infligido su maestro de Gramática, circunstancia que obraba en desprestigio del Instituto y que podía desalentar futuras vocaciones. La noticia de que los jesuitas habían asesinado al estudiante había provocado un gran tumulto contra ellos en la ciudad, del que solo la actuación del Gran Duque había conseguido salvarlos. La resurrección del novicio había permitido con su testimonio mostrar la inocencia de sus maestros y que había sido él, por su propia mano, el causante de su propia muerte, con lo que

...con este milagro tan patente trocaron el pueblo, y los padres del estudiante, todo su enojo en afición y estima de San Ignacio, y no menor milagro fue, que se trocasse el estudiante de tal modo, que agradecido a nuestro santo Padre, quiso ser su hijo y se entró en la Compañía, donde oy en día vive ${ }^{66}$.

Por el contrario, Nieremberg no atendió las recomendaciones para que rectificara los excesos al relatar otros milagros de Ignacio, carentes de toda justificación documental, como aquel en que hacía al fundador de la Compañía protagonista siendo un bebe, ante las dudas de sus progenitores, de al alzar su voz en la pila bautismal para darse asimismo por nombre Ignacio, situación que podían mover a la risa y burla de los lectores ${ }^{67}$.

Es posible que el exagerado triunfalismo con que Nieremberg relató la imagen de Ignacio esté en la base de los temores que llevaron a sus superiores

\footnotetext{
63 Sobre la censura en el seno de la Compañía véase BALDINI, 1992: 77-90.

64 NIEREMBERG, 1631a.

65 NIEREMBERG, 1645: Protesta del Autor.

66 NIEREMBERG, 1631b: 100.

67 NIEREMBERG, 1645: 4.
} 
romanos a censurar la obra. Pero no deja de resultar paradójica esta circunstancia si tenemos en cuenta que esta imagen de un Ignacio milagrero estaba en clara avenencia con la imagen oficial adoptada por la Compañía a raíz de los últimos compases del proceso de canonización de su fundador ${ }^{68}$. En efecto, como ha señalado Miguel Gotor, el deseo de conducir a una progresiva modificación de la religiosidad de los jesuitas que resultara más conforme a los designios confesionales de la monarquía pontificia, pasando de una espiritualidad con acentuados caracteres místicos y contemplativos sensibles al subjetivismo «alumbrado» en sus orígenes a otra de tipo más activo y práctico, cargado de elementos devocionales exteriores que el culto de Ignacio de Loyola permitiría valorizar al máximo, explica la renuncia que se hizo del planteamiento inicial de la biografía que de Ignacio hiciera el padre Ribadeneira, que había defendido su santidad en función exclusivamente de sus propias virtudes (Libro V de la Vida de Ribadeneira). Por orden del propio general Acquaviva, Virgilio Cepari puso en cuestionamiento esa opción antimilagrista y ensalzó, por el contrario, el relato de los prodigios efectuados por el fundador de los jesuitas en el relato conducente a su canonización, más acorde al modelo de santidad de la ortodoxia contrarreformista que el general italiano trataba de impulsar dentro de la orden y que terminó imponiéndose, aún con disgustó de los jesuitas españoles 69.

Fiel al principio de la «obediencia ciega», que reconocía como principio rector de la Compañía legado por el propio Ignacio ${ }^{70}$, Nieremberg no se desvió de aquella nueva orientación que hacía irreconocible a Ignacio de Loyola, hasta el extremo de convertirlo, en palabras de Hugnes Didier, en un «ser angélico, quien, santo, desde la cuna, no necesitó convertirse y gozó de facultades sobrenaturales, entre ellas las de levitación y bilocación» ${ }^{71}$. Como Ribadeneira, inició su relato con la visión providencialista de un Ignacio nacido para fundar una Compañía profetizada que había de luchar contra la herejía, extender con su apostolado por todo el orbe la fe católica y reformar las costumbres religiosas en su interior ${ }^{72}$. Tratará su imagen como la de una personalidad singular en carácter, fe y vida, solo posibles por un hombre tocado por

68 Sobre las vidas de Ignacio redactadas en aras de su canonización véanse las reflexiones de O’MALLEY, 2008: 1-34.

69 GOTOR, 2012, II: 1014-1019. La dificultad de definir la naturaleza de la espiritualidad ignaciana de los primeros tiempos sigue siendo un campo de controversia historiográfica entre los historiadores, avivada por los episodios de los procesos inquisitoriales que sufrió en los arranques de la Compañía su propio fundador. ¿Alumbradismo? ¿Herencia del humanismo erasmiano? Sobre la cuestión véanse los diferentes puntos de vista, entre otros, de O’MALLEY, 1993: 45-46; PASTORE, 2010: 279; o BATAILLON, 2010: 68.

70 NIEREMBERG, 1645: 26.

71 DIDIER, 1976: 120.

72 NIEREMBERG, 1645: 1-2. 
Dios. Pero a diferencia de aquél, Nieremberg no establecerá una asociación tan estrecha entre su vida y la propia trayectoria fundacional de la Compañía, rebajando la relevancia histórica de Ignacio. Así, despojará el relato de cualquier elemento que pudiera enturbiar su imagen —las dudas sobre las formas de su espiritualidad en sus orígenes que le llevarían en repetidas ocasiones ante los jueces inquisitoriales españoles, franceses e italianos, fueron totalmente silenciadas-, y apenas dedicará tres folios — el capítulo II— a reparar brevemente en algunos aspectos esenciales de su biografía: su ascendencia familiar, su herida en el sitio de Pamplona, su visita a Montserrat, su peregrinaje a Jerusalén, sus estudios en Alcalá y París y la obtención de la bula confirmatoria de la creación de la Compañía en 1540, antes de gobernarla por espacio de quince años ${ }^{73}$. El resto de su narración — que no dejó de aumentar tras la primera edición madrileña de 1631, más orientada hacia un público más amplio y popular en el que se pretendía alimentar la devoción por el nuevo santo que las sucesivas donde el acopio de nuevas informaciones tuvo como destino natural la lectura interna en los propios colegios de la Compañía-, la dedicará a fortalecer la imagen de un Ignacio de Loyola taumaturgo, profético y exorcista contra el demonio, figura que aparece cada vez con más relevancia en el relato como enemigo de la Compañía ${ }^{74}$; paladín de la devoción mariana y del inmacularismo ${ }^{75}$; tutelador espiritual sobre algunas órdenes religiosas femeninas — con especial mención de las discípulas de Teresa de Jesús, como en el caso de la florentina Margarita de Pazzi, beatificada por Urbano VIII en 1628-76; y de ardiente cristocentrismo que impregnará a toda la Compañía. Esta última circunstancia llevará a Nieremberg a no negar la visión hebreocéntrica de la historia, poniendo incluso en boca de Ignacio algunas peligrosas expresiones susceptibles de ser malinterpretadas en un contexto convulso de creciente animadversión antisemita despertada en la opinión pública de aquellos años por la decisión de Olivares de recurrir a financieros judíos tras la bancarrota de $1627^{77}$, y que algunos, posteriormente ${ }^{78}$, atribuirían a la mala influencia de los confesores jesuitas del conde-duque:

Y aunque en toda España se tenga por muchas razones, por cosa afrentosisima descender de los Hebreos, con todo esso San Ignacio, que era muy limpio, y noble, dezia, por el amor que tenía a IesuChristo, y deseo de ser en todo humillado, y oprobio de los hombres, que se holgara ser de aquel linaje, para ser aun por este

73 NIEREMBERG, 1645: 5-7.

74 NIEREMBERG, 1645: 78-82.

75 NIEREMBERG, 1645: 9-10 y 53-65.

76 NIEREMBERG, 1645: 107-112.

77 PULIDO SERRANO, 2002.

78 Sería el caso de Melchor de Macanaz, ya en el siglo XVIII, como apuntó hace años Gregorio Marañón en su estudio sobre el conde-duque de Olivares. MARAÑON, 1980: 184. 
camino más cercano, según la carne, a Christo, y su Madre, siendo de su parentela, y mas despreciado del mundo, lo qual procedía del ardentíssimo amor que les tenía ${ }^{79}$.

Con todo, la mayor preocupación de Nieremberg sería la defensa de la Compañía frente a los ataques de sus detractores, especialmente de los dominicos, que periódicamente cuestionaban la ortodoxia de algunos de los escritos ignacianos y en particular los Ejercicios Espirituales. Ciertamente a Nieremberg se le haría muy difícil hablar de aquel librito de Ignacio sin dar la lista de los teólogos que habían respaldado su ortodoxia (Teofilo Bernardino, el propio Paulo III, S. Carlos Borromeo, Fray Luis de Granada, el Abad Ludovico Blosio, el dominico maestro Mancio, don Bartolomé de Torres, Francisco de Villanueva, Francisco de Estrada...). Tales precauciones demuestran que, a pesar de su celo hagiográfico, no estaba seguro del valor teológico de los escritos ignacianos, pues

es cosa de espanto, que un hombre idiota, y sin letras, como por entonces era San Ignacio, quando se determinó fundar la Compañía....sacase una obra tal, que la tuvieron por idea perfectísima de semejantes obras, los Soles de Teología y Filosofía, santo Tomas y Platón ${ }^{80}$.

Por ello, para legitimar la posición ortodoxa de los jesuitas surgida de un «ignorante» como San Ignacio, Nieremberg recurrirá al encumbramiento de Ignacio en boca nada menos que del propio Santo Tomas, que lo profetizó poniéndolo a la altura de aquellos grandes patriarcas de la Iglesia que había recibido de manera directa la palabra de Dios:

lo primero [Dios] dotó su alma de una sabiduría divina infundiéndola un altissimo conocimiento de la divinidad, representándole unas veces las tres divinas personas, otras algunas dellas, y la misma divina Essencia, de manera que como señala don Sancho de Ávila, Obispo de Plasencia, y el Padre Diego Álvarez con otros Doctores señalados, así en Teología Escolástica como Mística, y conocidos en el mundo por sus escritos, han afirmado que si es verdadera la opinión de Santo Tomas y de insignes Padres de la Iglesia, que juzgaron que algunos santos estando en vida vieron la Essencia divina claramente como Moyses, San Pablo, San Agustín, san Benito, que lo mismo se ha de decir de san Ignacio ${ }^{81}$.

Nieremberg establecía así el nexo irreprochable de la orden con toda la Historia de la Iglesia a su más alto nivel, la de aquellos, los patriarcas, que habían tenido una visión directa con Dios, y lo hacía desde la argumentación

\footnotetext{
79 NIEREMBERG, 1645: 31; DIDIER, 1976: 108.

80 NIEREMBERG, 1645: 98.

81 NIEREMBERG, 1645: 7-8.
} 
de quien había surgido la rival religiosa más importante de los jesuitas, como era el propio Santo Tomás.

No obstante, ante el delicado equilibrio en que se movía en aquellos tiempos la Compañía entre las cortes de Madrid y Roma ${ }^{82}$, el general Vitelleschi recomendó cautela a la hora de autorizar nuevas ediciones de aquella vida sin una revisión previa. Es posible que esta sea la razón por la que la Vida de Ignacio no encabezó el primero de los volúmenes de la serie de los Varones Ilustres que apareció en 1643, y que lo hiciera en el tercero, en 1645, ya muertos Urbano VIII y Vitelleschi, en un clima de cierta distensión entre Roma y Madrid, promovido por sus sucesores respectivos, Inocencio X y Vicente Carafa, y contando con la aprobación y censura favorable del padre Juan Ponce de León, calificador del Santo Oficio y visitador de las librerías de España, dándole respaldo ${ }^{83}$. Como en otros episodios parecidos, el recurso a la Inquisición española también resultó válido a Nieremberg para escapar tanto de la inquisición romana como de la propia de la Compañía. Con todo, las correcciones que hiciera de aquélla no parece que satisfacieran del todo a la Congregación del Índice, pues, por decreto del 18 de diciembre de 1646, ésta ordenó que el libro fuera puesto en el Índice con la cláusula donec corrigatur ${ }^{84}$, es decir, prohibiendo su circulación mientras no fuese expurgado, lo que en muchas ocasiones por las dilaciones en las revisiones podía significar en la práctica su retiro definitivo.

Pero más allá de estas circunstancias que afectaron a la biografía de Ignacio, las Vidas Ilustres son también, a nuestro juicio, el testimonio disimulado de los desencuentros que continuaban persistiendo entre los jesuitas españoles y el gobierno de los generales romanos, y que volvieron a salir a la luz durante la crisis de aquellos años treinta. Desde esta perspectiva, algunas de estas Vidas transpirarían una cierta lectura "política» en el propio seno de la Compañia, expresada en el trato diferenciado que Nieremberg dio, por ejemplo, a las biografías de algunos de sus generales. Mientras se resolvía el tema de la censura interna de la Vida de Ignacio, incluyó en el primer tomo las vidas de los generales Lainez, Borja y Acquaviva, desigualmente tratadas en extensión y ubicación ${ }^{85}$. Ni Mercuriano ni Vitelleschi tuvieron cabida —a pesar de los treinta años de mandato de este último-, en los sucesivos volúmenes, incluidos los que Andrade publicó entre 1666 y 1667. Sólo sería incluida la de su sucesor, Vicente Carafa, de breve gobierno, aprovechando como base documental la biografía que Bartoli había hecho de él en Roma en 1651.

82 VISCEGLIA, 2010: 41-45.

83 NIEREMBERG, 1645: Aprobación.

84 ASTRAIN, 1916, V: 108.

85 La de Diego Lainez ocupa 27 páginas y la de Francisco de Borja 59, siendo la novena y la quinceava biografías del libro, mientras que la de Acquaviva se limita a 3 páginas y ocupa la posición número 49. 
En aquel primer tomo, la imagen de Acquaviva quedaba perfectamente contrapuesta a la de los últimos generales españoles que le precedieron. Su principal virtud — puede decirse que prácticamente la única — había sido la de su «superior talento que Dios Nuestro Señor le avia comunicado para el gobierno» ${ }^{86}$. Nieremberg lo presenta como el «sabio piloto» que supo orientar la nave de la Compañía durante sus largos treinta y cuatro años de gobierno, «en las adversidades y prosperidades, que padeció muchas en su tiempo (...), en que nunca dexó de governarla y el irla siempre guardando y adelantando» ${ }^{87}$. Acquaviva fue el guía que orientó la contrarreforma dentro del Instituto con el rígido disciplinamiento que impuso su talante normativista, pues como dirá de él, su «primera escritura fue la de las leyes, y por averse señalado el Padre Claudio Aquaviva en escribir ordenanzas, y leyes prudentísimas, con que ilustró muchas cosas de nuestro instituto, merece ser contado entre los nobles escritores de su siglo» ${ }^{88}$.

Ahora bien, la mordaz ironía de Nieremberg también se proyectará sobre su figura, al recordar lo novel de su elección como Prepósito General, no teniendo aun 40 años de edad, y «siendo el más moço de todos los Padres que se hallaron en la Congregación General del año 1581...prefiriéndose a muchos Padres muy graves y antiguos de venerables canas» ${ }^{89}$. Y, especialmente cuando recuerda que la quinta y sexta Congregación general, ordenaron «se hiciesse inquisición de su modo de govierno» ${ }^{90}$.

En efecto, las congregaciones de 1593 y 1608 mostraron bien a las claras las heridas abiertas entre el General y los jesuitas españoles tras más de treinta años de su gobierno, ratificando, en general, el principio de la autoridad jerárquica dentro de la misma y la dependencia última del papa. Durante aquel tiempo Acquaviva había comenzado a enfrentarse a los nuevos retos que implicaba dirigir con mano firme una orden que se desbordaba espacialmente con el paso decisivo de su universalización planetaria y que precisaba, por ello, reforzar la centralidad de su gobierno romano, rehuyendo de los particularismos del pasado (el desafío del autonomismo expresado por los memorialistas españoles en el arranque de su gobierno) ${ }^{91}$, o adaptándose a los nuevos tiempos de la ortodoxia tridentina, superando su primigenia naturaleza espiritual plagada por las dudas del alumbradismo y por la amplia presencia de conversos en su seno. Este fue el pulso dirimido en aquellas reuniones entre el General romano y los disidentes hispánicos, que dieron expresión al

86 NIEREMBERG, 1643b: 645.

87 NIEREMBERG, 1643b: 646.

88 NIEREMBERG, 1643b: 644.

89 NIEREMBERG, 1643b: 645.

90 NIEREMBERG, 1643b: 646.

91 GARCIA CARCEL, 2000: 383-404. 
problema del gobierno interno de la Compañía y de la obediencia en la misma: el anhelo de los jesuitas españoles por tener, al menos un procurador especial en Roma que se ocupase de los asuntos españoles; las resistencias a la expulsión de los conversos de la Compañía, expresadas por el padre Ribadeneira al general; la delicada situación financiera de muchos de los colegios españoles; la relajación de las costumbres de muchos jesuitas, más inclinados por las ventajas temporales de sus servicios cortesanos que por la dedicación a los asuntos apostólicos propios de su condición religiosa; o el controvertido tema de la «corrección fraterna», que establecía siempre la obligación de la delación hacia el superior de cualquier falta, pero no de éste hacia el inferior, formaron parte del conjunto de temas que allí se abordaron ${ }^{92}$.

No era pues baladí que Nieremberg recordara, a modo de advertencia, aquellas fracturas de comienzos de siglo y que parecían reabrise en aquella crisis de los años treinta. Dado que el manuscrito de aquel primer tomo debió ser enviado a Roma para su revisión en 1638, era posible que el general Vitelleschi pudiera reflexionar sobre cual era el modelo más ilustre de virtud a seguir al contrastar políticamente la figura de Acquaviva con la de los otros generales españoles que le habían precedido, y en especial con la de Diego Lainez, que era la que más se aproximaba a la identificación que Nieremberg podía hacer del perfecto general.

Silenciada cualquier referencia a su origen converso, Nieremberg señalaba entre las cualidades más notables de Lainez la del obrero perfecto y excelente de la Compañía, el ejemplo de cómo trabajar con dedicación absoluta sin torcerse con amenazas y halagos, con autentica «obediencia ciega», que siempre había guardado hacia Ignacio, pero con la firmeza, asimismo, del rechazo de dignidades como la que le propusira Paulo IV con su deseo de convertirlo en cardenal ${ }^{93}$. Pero sobre todo admiraba Nieremberg de Lainez el modelo de sabiduría que transmitía, forjado no en la inspiración divina insuflada, como en el caso de Ignacio, sino en la labor paciente del trabajo intelectual entre libros, con la que nuestro jesuita se identificaba plenamente:

«Tuvo toda la vida una ansia insaciable de saber, y aun desde muy niño deseo entrañablemente alcançar el don de la sabiduría. Y siendo mancebo le pedía a nuestro Señor, con instancia, ayudándose con él para ello, con no perder jamás punto, ni ocasión de estudiar; de donde vino a leer y resumir casi todos los Autores de todas las facultades, que entre tantas ocupaciones es cosa que pone de espanto los libros que leyó, no solo Escolásticos, Morales y políticos, sino también de prudencia, devoción y espíritu. Y porque de otra manera parece imposible llegar a sa-

92 ASTRAIN, 1909, III: 660-665.

93 NIEREMBERG, 1643 b: 198 y 219. 
ber tanto, juzgaron muchos que Dios nuestro Señor le había infundido sobrenaturalmente la sabiduría» ${ }^{94}$.

Era de aquel paciente aprendizaje intelectual de donde surgía la figura del polemizador victorioso contra los herejes que había sido Lainez, la del mediador requerido en las disputas conciliares por su sabiduría para alumbrar en materia teológica a los miembros de la Iglesia, como los jesuitas del tiempo de Nieremberg continuaban haciendo ${ }^{95}$. Lainez podía servir así de modelo tanto para los propios compañeros españoles como para generales como Vitelleschi. Aquél tenía en Lainez el ejemplo perfecto de superior paternal que equilibraba con sabiduría dulzura y disciplina ${ }^{96}$.

La idea de confrontar las biografías de los generales como estrategia de crítica disimulada hacia la acción de alguno de ellos no era nueva. Nieremberg, como en tantas otras cosas, imitó lo hecho por Ribadeneira en 1594 cuando, coincidiendo con la celebración de la quinta congregación, añadió la biografía de Diego Lainez a las de Ignacio de Loyola (1572) y de Francisco de Borja (1592), como modelo que podía seguir el general Acquaviva ${ }^{97}$.

Es por ello, que las Vidas Ilustres de Nieremberg y Andrade no pueden ser consideradas como un recopilatorio hagiográfico más, de carácter más o menos fantasioso, redactadas al calor de las estrategias diseñadas por la Compañía con motivo de la celebración de su primer centenario para fortalecer el sentido corporativo de sus miembros y defender de paso su imagen ante el clima creciente de hostigamiento intelectual desatado contra ellos desde los inicios del Seiscientos - la famosa Monita Secreta, sería publicada por primera vez en Cracovia en 1613- . Fue eso, sin duda, pero también un instrumento literario de lecturas múltiples, también «políticas» en el seno de la propia Compañía, que sirvió para expresar el complejo contexto histórico que tuvieron que vivir los jesuitas españoles en los años centrales del reinado de Felipe IV, en medio de los difíciles equilibrios para navegar entre su lealtad a la Corona y la siempre complicada cuestión de la obediencia que imponía el cuarto voto respecto a Roma.

\section{BibLIOGRAFÍA}

Alabrús Iglesias, Rosa Maria, «Misiones en Japón. Las órdenes religiosas ante los martirios en los siglos XVI y XVII», en Rosa Maria Alabrús (ed), La vida cotidiana y la sociabilidad de los dominicos, Barcelona, Arpegio, 2013: 237-261.

94 NIEREMBERG, 1643b: 206.

95 NIEREMBERG, 1643b: 204-207.

96 NIEREMBERG, 1643b: 220.

97 MORENO MARTINEZ, 33 (Universidad de Valladolid, 2013): 79-86. 
Andrade, Alonso, Varones Ilustres en Santidad, Letras y zelo de las almas de la Compañía de Jesús, Madrid, José Fernández de Buendía, V, 1666.

Andrade, Alonso, Varones Ilustres en Santidad, Letras y zelo de las almas de la Compañía de Jesús, Madrid, José Fernández de Buendía, VI, 1667.

Armogathe, Jean Robert, «La fábrica de los Santos. Causas españolas y procesos romanos de Urbano VIII a Benedicto XIV (Siglos XVII-XVIII)», en Marc Vitse (ed), Homenaje a Henri Guerreiro. La hagiografía entre historia y literatura en la España de la Edad Media y del Siglo de Oro. Madrid, Universidad de Navarra/ Editorial Iberoamericana, 2005: 149-168.

Astrain, Antonio de, Historia de la Compañía de Jesús en la Asistencia de España, Madrid, Razón y Fe, 5 vols., 1902-1916.

Baldini, Ugo, Legem Impone Subactis Studi su Filosofia e scienza dei gesuiti in Italia, 1540-1632. Roma, Bulzoni Editore, 1992.

Bataillon, Marcel, Los jesuitas en la España del siglo XVI, Valladolid, Ed. Junta de Castilla y León, 2010.

Ballesteros Robles, Luis, Diccionario Biográfico Matritense, Madrid, 1912.

Betrán Moya, José Luís, «Unus non sufficit orbis: La literatura misional jesuita del Nuevo Mundo», Historia Social, 65, (Valencia, 2009): 167-185.

Betrán Moya, José Luís, «Vidas memorables jesuitas: Juan Sebastián de la Parra, provincial del Perú (1546-1622)», en Ángela Atienza López (ed), Iglesia memorable. Crónicas, historias, escritos... A mayor Gloria. Siglos XVI-XVIII, Madrid, Silex, 2012: 117-148.

Bireley, Robert, Religion and Politics in the Age of the Contrarreformation: Emperor Ferdinand II, William Lamormaini S.I., and the Formation of Imperial Policy, Chapel Hill 1981 (reprint, 2010), and Maximilian von Bayern, Adam Contzen, S.J., und die Gegenreformation in Deutschland 1624-1635, Göttingen, 1975.

Bireley, Robert, «Acquaviva's «Instruction for confessors of princes» (1602/1608): A documents and its interpretation», en Martínez Millán, José; Pizarro Llorente, Henar; Jiménez Pablo, Esther (coords.), Los jesuitas. Religión, política y educación (siglos XVI-XVIII), Madrid, Universidad Pontifica Comillas, 2012, Vol. I: 45-68.

Broggio, Paolo, La teologia e la politica. Controverse dottrinale, Curia romana e Monarchia spagnola tra Cinque e Seicento, Firenze, Leo S. Olsehki Editore, 2009.

Burke, Peter, «How to be a Counter-Refomation Saint», en Peter Burke (ed), The Historical Antropology of Early Modern Italy, Cambridge, 1987: 48-62.

Burrieza Sánchez, Javier, «La Antigua Compañía de Jesús (siglos XVI-XVIII)», en Teófanes Egido (coord.), Los jesuitas en España y en el mundo hispánico, Madrid, Marcial Pons, 2004: 27-223.

Catto, Michela, La Compagnia divisa. Il dissenso nella Compagnia di Gesu fran Cinque e Seicento, Milan, 2009.

Catto, Michela, «The Jesuit memoirists: How the company of Jesus contributed to anti-jesuitism», en Martínez Millán, José; Pizarro Llorente, Henar; Jiménez Pa- 
blo, Esther (coords.), Los jesuitas. Religión, política y educación (siglos XVIXVIII), Madrid, Universidad Pontifica Comillas, 2012, Vol. II: 927-941

Caro Baroja, Julio, Las formas complejas de la vida religiosa (Religión, sociedad y carácter en la España de los siglos XVI y XVII), Madrid, Sarpe, 1985.

Chaparro, Sandra, «Juan Eusebio de Nieremberg (1595-1658). Un intelectual de la monarquía católica hispana»«, Razón y Fe, № 1358 (Madrid, diciembre 2011): 427-435.

Delgado Casado, Juan, Diccionario de Impresores españoles (siglos XV-XVII), Madrid, Arcos Libros, 2 Volms. 1996

Darnis, Pierre, «La lectura del espejo sagrado: una hermenéutica del Flos Sanctorum de Pedro de Ribadeneira», en Marc Vitse (ed.), Homenaje a Henri Guerreiro. La hagiografía entre historia y literatura en la España de la Edad Media y del Siglo de Oro. Madrid, Universidad de Navarra/ Editorial Iberoamericana, 2005: 435-451.

Dekoninck, Ralph, Ad Imaginem. Status, foctions et usages de l'image dans la littétarature spirituelle jésuite du XVIIe siècle, Ginebra, Librairie Droz, 2005.

Didier, Hugues, Vida y pensamiento de Juan E. Nieremberg, Madrid, Universidad pontificia de Salamanca / Fundación Universitaria Española, 1976.

Dupront, Alphonse, Du sacre:croissades et pélegrinages, images et langages, París, Gallimard, 1996.

Éliade, Mircea, Le mythe de l'eterne retour, París, Gallimard, 1969.

Fumaroli, Marc, «The Fertility and The Shortcomings of Renaissance Rhetoric : The Jesuist Case», en O’Malley, John W, S.I. ; Alexander Bailey, Gauvin; Harris, Steven J ; Kennedy, T. Frank. S.I. (eds), The Jesuits. Cultures, Sciences, and the Arts 1540-1773. Toronto, University of Toronto Press, 2 vols., 1999: 90-106.

García Cárcel, Ricardo, «La crisis de la Compañía de Jesús en los últimos años del reinado de Felipe II», en Luis A. Ribot García, La Monarquía de Felipe II a debate, Madrid, 2000: 383-404.

García Estébanez, Albino, «Ejercicios espirituales: método», en José García de Castro (dir.), Diccionario de Espiritualidad Ignaciana, Bilbao, Ediciones Mensajero, 2 vols. 2007.

Guillausseau, Axelle, «Los relatos de milagros de Ignacio de Loyola», Criticón, Núm. 99 (Universidad de Toulouse, 2007): 5-56.

Gotor, Miguel, «La riforma dei procesi di canonnizzazzione della carte del Sant'Ufficio (1588-1642)», en L'Inquisizione e gli storici: un candiere aperto. Tavola rotonda nell'ambito della conferenza annuale de recerca (24-25 giugnio 1999), Roma, 2000: 279-288.

Gotor, Miguel, «Hagiografía y censura libraria: el Quinto capítulo sobre los milagros de la Vida de Ignacio de Loyola de Pedro de Ribadeneira entre Corte de Reyes y obediencia romana», en Martínez Millán, José; Pizarro Llorente, Henar; Jiménez Pablo, Esther (coords.), Los jesuitas. Religión, política y educación (siglos XVIXVIII), Madrid, Universidad Pontifica Comillas, 2012, tomo II: 1007-1027. 
Lozano Navarro, Julián J. La Compañía de Jesús y el poder en la España de los Austrias, Madrid, Cátedra, 2005.

Marañón, Gregorio. El Conde-Duque de Olivares. La pasión de mandar. Madrid, Espasa-Calpe, 1980.

Medeiros Rodrigues, Luis Fernando, «Ad omnium solatium et aedificationem. Os menologios na Companhia de Jesus: gênese, desenvolvimento e reforma», en Anais do XXVI Simposio Nacional de Historia -ANPUH, Sâo Paulo, julho 2011: 1-23.

Moreno Martínez, Doris, «Las sombras de la Compañía de Jesús en la España Moderna, siglos XVI-XVII», en José Luis Betrán (ed.), La Compañía de Jesús y su proyección mediática en el mundo moderno, Madrid, Silex, 2010: 77-113.

Moreno Martínez, Doris y Peña Díaz, Manuel, «El jesuita Juan Bautista Poza y la censura», en Lavenia, Vicenio y Paolin, Giovanna, Riti di passagio, storie di giustizia, Pisa, Edizioni della Normale, 2011, vol. III: 159-170.

Moreno Martínez, Doris, «La aportación española al debate sobre la obediencia ciega en la Compañía de Jesús durante el Papado de Sixto V (1585-1590)», Investigaciones históricas: Época moderna y contemporánea, $\mathrm{N}^{\mathrm{o}} 33$ (Universidad de Valladolid, 2013): 63-88.

Najera, Manuel de, Sermón que predicó el padre Manuel de Naxera predicador de su Majestad en las piadosas exequias que consagró a la memoria del P. Iuan Eusebio Nieremberg el Ilustrísimo Señor Don Cristóbal Crespi de Baldaura, vicecanciller del Supremo y Real Consejo de Aragón, Madrid, Andrés García de la Iglesia, 1658.

Negredo del Cerro, Fernando, Los predicadores de Felipe IV. Corte, intrigas y religión en la España del Siglo de Oro, Madrid, Actas, 2006.

Negredo del Cerro, Fernando, «La Compañía de Jesús y el Consejo de Estado bajo Felipe IV. Reflexiones a propósito del incidente del Padre Puente Hurtado», en Martínez Millán, José; Pizarro Llorente, Henar; Jiménez Pablo, Esther (coords.), Los jesuitas. Religión, política y educación (siglos XVI-XVIII), Madrid, Universidad Pontifica Comillas, 2012, Tomo I: 155-182.

Nieremberg, Juan Eusebio, Vida de San Ignacio de Loyola fundador de la Compañía de Jesús. Resumida, y añadida de la Bula, y Relaciones de su Canonización, y de otros graves Autores. Madrid, Imprenta del reino, 1631a.

Nieremberg, Juan Eusebio, Vida del Patriarca San Ignacio de Loyola, Fundador de la Compañía de Jesús. Resumida, y añadida de la Bula, y Relaciones de su Canonización, y de otros graves Autores. Revista y acrecentada por el mismo Autor. Zaragoza, Hospital Real y General de Nuestra Señora de Gracia, 1631b

Nieremberg, Juan Eusebio, Vida del glorioso Patriarcha San Ignacio de Loyola. Por el Padre Juan Eusebio Nieremberg de la misma Compañía. Tercera impresión revista por el mismo Autor, y aumentada con la vida de San Francisco Xavier Apóstol de la India, Religioso de la misma Compañía de Jesús, Madrid, Imprenta del reino, 1636. 
Nieremberg, Juan Eusebio, Causa y remedio de los males públicos, Madrid, Maria Quiñones, 1642.

Nieremberg, Juan Eusebio, Corona virtuosa y virtud coronada, en que se proponen los frutos de la virtud de un Príncipe justamente con los heroicos exemplos de las Virtudes de los Emperadores de la Casa de Austria y Reyes de España, Madrid, Francisco Maroto, 1643a.

Nieremberg, Juan Eusebio, Ideas de Virtud en algunos claros varones de la Compañía de Jesús. Para los religiosos della, Madrid, Maria de Quiñones, Vol. I, $1643 b$.

Nieremberg, Juan Eusebio, Firmamento religioso de luzidos astros, en algunos claros varones de la Compañía de Jesús, Madrid, Maria de Quiñones, Vol. II, 1644.

Nieremberg, Juan Eusebio, Honor del Gran Patriarca San Ignacio de Loyola, fundador de la Compañía de Jesús, en que se propone su vida, y la de su disciplo el apóstol de Indias San Francico Xavier. Con la milagrosa Historia del admirable Padre Marcelo Mastrilli, y las noticias de gran multitud de hijos del mismo San Ignacio, varones clarísimos en santidad, dotrina, trabajos y obras maravillosas en servicio de la Iglesia, Madrid, Maria de Quiñones, Vol. III, 1645.

Nieremberg, Juan Eusebio, Vidas ejemplares y venerables memorias de algunos claros varones de la Compañía de Iesus, Madrid, Alonso de Paredes, Vol. IV, 1647.

O’Malley, John W, Los primeros jesuitas, Bilbao, Ed. Mensajero, 1993.

O’Malley, John W, «The many lives of Ignatius of Loyola future saint», en Constructing a sanit throug images. The 1609 illustrated biography of Ignatius of Loyola, Philadelphia, Saint Joseph’s University Press, 2008 : 1-34.

Osswald, Maria Cristina y Hernández Palomo, José J., «Aspectos del culto a Ignacio de Azevedo y sus treinta y nueve compañero mártires en 1570», en José J. Hernández Palomo y José del Rey Fajardo (coord), Sevilla y America en la historia de la Compañía de Jesús. Homenaje al P. Francisco de Borja Medina Rojas, S.I. Cordoba, 2009: 129-153.

Palau y Dulcet, Antonio. Manual del Librero Hispano-Americano, Barcelona, Librería Palau, 1958.

Pastore, Stefania. Una herejia española. Conversos, alumbrados e Inquisición (14491559), Madrid, Marcial Pons, 2010.

Pulido Serrano, Juan Ignacio, Injurias a Cristo. Religión, política y antijudaismo en el siglo XVII, Alcalá, Instituto Internacional de Estudios Sefardíes y Andalusíes, Universidad de Alcalá, 2002.

Ribadeneira, Pedro, Flos sanctorum, o Libro de la vida de los santos/ escrito por Pedro de Ribadenieria; y a la fin de la segunda parte van añadidas muchas vidas de santos que hazen parte, escritas por Juan Eusebio Nieremberg. Barcelona, Sebastián de Cormellas, 1643.

Rico Callado, Francisco Luis, «La Imitatio Christi y los itinerarios de los religiosos: hagiografía y prácticas espirituales en la vocación religiosa en la España Moderna», Hispania Sacra, LXV, Extra I (enero-junio 2013): 127-152. 
Rubial García, Antonio, La santidad controvertida, México, Fondo de Cultura Económica, 1999.

Simón Díaz, José, Historia del Colegio Imperial de Madrid, Madrid, Instituto de Estudios Madrileños, 1992.

Sommervogel, Carlo, Bibliothèque de la Compagnie de Jesús, París, Alphonse Picard, 1890-1932.

Vicens, Fr. Gaspar, Miscelánea Político-Eclesiástica, Biblioteca Universitaria de Barcelona, Mss. 1008-1010.

Vauchez, André, La sainteté en Occident aux derniers siècles de Moyen âge, Roma, École française de Rome, 1988.

Visceglia, M. Antonietta, « Congiurarono nella degradazione del Papa per via di Un Concilio » : La protesta del Cardinale Gaspare Borgia contro la politica papale nella guerra dei Tret'Anni, Roma Moderna e contemporanea, vol. XI, $\mathrm{n}^{\circ}$ 1-2 (2003): 167-193.

Visceglia, M. Antonietta, Roma papale e Spagna. Diplomatici, nobili e religiosi tra due corti, Roma, Bulzoni Editore, 2010.

Recibido: 31/12/2013

Aceptado: 17/06/2014 